\title{
Orbital plasmablastic lymphoma: a clinico- pathological correlation of a rare disease and review of literature
}

This article was published in the following Dove Press journal:

Clinical Ophthalmology

10 December 2012

Number of times this article has been viewed

\author{
Kaustubh Mulay' \\ Mohammad Javed $\mathrm{Ali}^{2}$ \\ Vijay Anand Reddy ${ }^{2}$ \\ Santosh G Honavar ${ }^{2}$ \\ 'Ocular Pathology Service, LV Prasad \\ Eye Institute, Hyderabad, Andhra \\ Pradesh, India; ${ }^{2}$ Oncology Service, \\ LV Prasad Eye Institute, Hyderabad, \\ Andhra Padresh, India
}

\begin{abstract}
Ocular involvement by plasmablastic lymphoma is extremely rare with very few reports in the literature. Its morphological and immunological resemblance to plasma cell myeloma makes it a diagnostic challenge, while its clinical course, which is characterized by recurrence and death, makes therapy a challenge for clinicians. We present three cases of plasmablastic lymphoma, each of which has distinct clinicoradiological features, and we also review the literature on orbital plasmablastic lymphomas.
\end{abstract}

Keywords: plasmablastic lymphoma, ocular, myeloma, orbit

\section{Introduction}

Ocular adnexal lymphomas are rare, accounting for only $1 \%$ to $2 \%$ of all lymphomas. ${ }^{1}$ The current World Health Organization classification recognizes plasmablastic lymphoma (PBL) as a distinct subtype of diffuse large B-cell lymphoma (DLBCL), characterized by the presence of neoplastic cells resembling B immunoblasts, but that have immunophenotypic features of plasma cells. ${ }^{2}$ PBL was first described to involve the oral cavity of predominantly human immunodeficiency virus (HIV)positive patients. ${ }^{3}$ Recently, several reports and case series have published the occurrence of PBL in other anatomical locations and in HIV-negative patients. ${ }^{4-17}$ Ocular involvement by PBL is extremely rare with very few reports in the literature. ${ }^{9-15}$ Its morphological and immunological resemblance to plasma cell myeloma makes it a diagnostic challenge, while its clinical course, which is characterized by recurrence and death, makes therapy a challenge for clinicians. We present three cases of PBL, each of which has distinct clinicoradiological features, and we also review the literature on orbital PBLs.

\section{Case reports Case I}

A 45-year-old previously healthy woman was referred to the ocular oncology clinic with a history of proptosis of the right eye for 6 months and diminished vision in the right eye for 2 months. At presentation, her best corrected visual acuity (BCVA) was limited to finger counting in the right eye. Severe proptosis of the right eye was noted with restriction of ocular motility in all directions (Figure 1A). Fundus examination of the right eye showed macular folds, a hyperemic disc, and dilated tortuous vessels, suggesting globe indentation and compressive optic neuropathy. A firm, hard, nontender mass was palpable in the superolateral aspect of the orbit on the right side with erythematous
Correspondence: Santosh G Honavar Oncology Service, LV Prasad Eye Institute, Road No 2, Bajara Hills, Hyderabad - 500034, India

Tel $+9|40306| 2622$

$\mathrm{Fax}+91402354827$ I

Email honavar@lvpei.org 
skin. Resistance was observed on retropulsion. Computerized tomography of the orbit showed a well-defined, large soft tissue mass, $4.0 \mathrm{~cm} \times 3.0 \mathrm{~cm} \times 2.6 \mathrm{~cm}$ in size, confined to the superolateral aspect of the right orbit with significant bony erosion involving the lateral wall with contiguous extension into the temporal fossa (Figure 1B).

Microscopic examination showed a diffuse tumor composed of discohesive, large, round lymphoid cells with moderate amounts of amphophilic cytoplasm, eccentric to the central nucleus, and a prominent nucleolus in many of the cells (Figure 2A). A significant population of tumor cells had a plasmacytoid appearance, and both normal and abnormal mitotic figures were seen. Immunostaining revealed no immunoreactivity for CD20 (Figure 2B) and CD45, but a strong, membranous expression of CD138 was noted (Figure 2C). The Ki-67 labeling index was 98\% (Figure 2D). A diagnosis of PBL was confirmed. Serum protein electrophoresis was within normal limits. Chest X-ray and systemic examination were normal. A bone marrow aspiration and

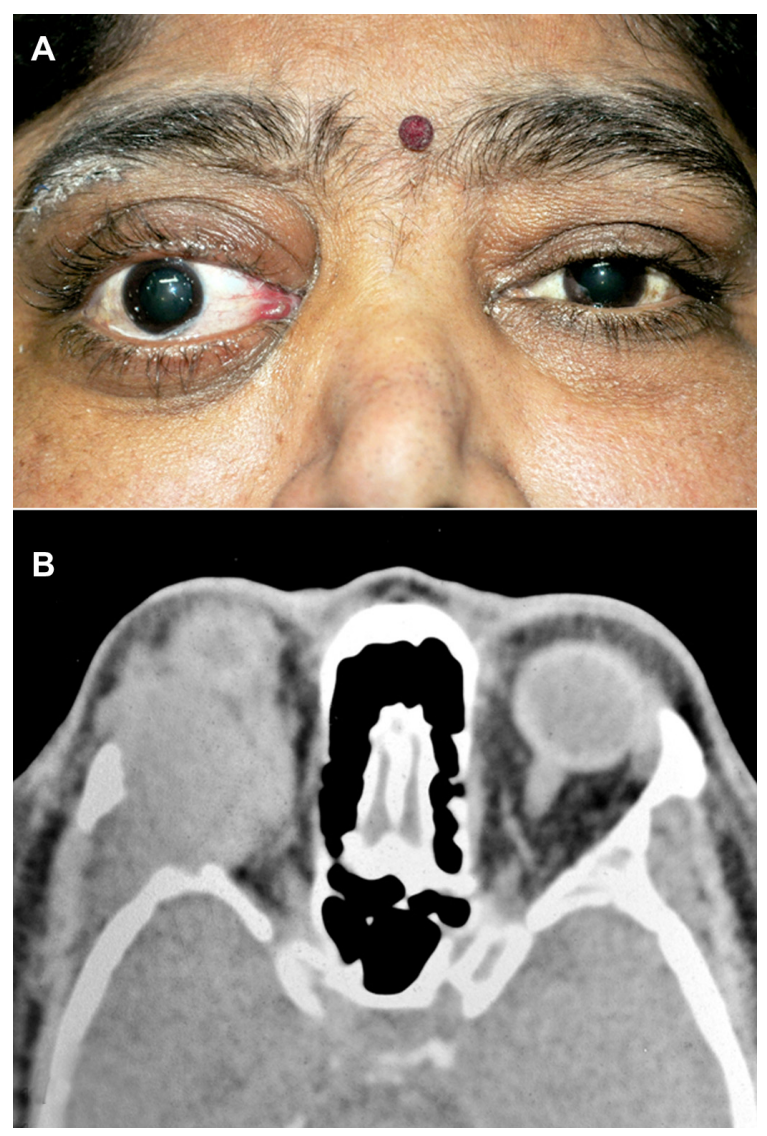

Figure I External photograph and axial CT scan of the same patient. External photograph of the patient showing right eye proptosis with periocular swelling and mild conjunctival congestion (A). CT scan, axial cut, of the same patient showing a large mass occupying the lateral quadrant of the orbit with erosion of the lateral wall and extension into the temporal fossa (B).

Abbreviation: $\mathrm{CT}$, computerized tomography. trephine biopsy were performed, which was normal. Our patient was staged as Ann Arbor 1A. An HIV screening test was performed and was found to be negative. The patient died within a week following diagnosis, even before further treatment could be initiated.

\section{Case 2}

A 45-year-old Indian male was referred to our oncology clinic with protrusion of the left eye, as well as associated redness, watering, and pain. At presentation, his BCVA was $20 / 25$ in the right eye and limited to light perception in the left eye. Conjunctival chemosis was observed with severe proptosis of the left eye (Figure 3A). Fundus examination could not be performed. Computed tomography showed a large hypodense mass in the anterior orbit on the superior and superolateral aspects of the globe. The mass indented the globe and was seen causing bony destruction with intracranial extension involving the frontal sinus and the ethmoid sinus (Figure 3B). Since the patient had a history of severe weight loss in the past 3 months, an HIV screening test was performed and was found to be positive.

Microscopic examination of the incision biopsy showed a diffuse tumor composed of a monotonous population of plasmacytoid cells with eccentric nuclei and a conspicuous to prominent nucleolus. Mitotic activity was brisk. Immunohistochemically, CD3, CD20, and CD5 were found to be negative. The tumor cells expressed strong membranous immunoreactivity for CD138 and weak reactivity for levocyte common antigen (LCA) (CD45). The Ki-67 index was close to $100 \%$. No light chain restriction was seen. Morphology and immunostaining patterns were confirmative of a PBL.

Bone marrow aspiration done as part of the staging protocol revealed involvement by PBL. Ultrasonography of the abdomen revealed multiple deposits in the liver. Serum lactate dehydrogenase was normal. Our patient was thus staged as Ann Arbor 4.

He was commenced on highly active antiretroviral therapy (HAART) as well as on the cyclophosphamide, hydroxydanorubicin, oncovin, and prednisone (CHOP) regimen. The patient refused chemotherapy and died 6 months following presentation.

\section{Case 3}

A 48-year-old Indian male presented with complaints of pain, redness, and watering in the left eye for the previous 3 days. At presentation, his BCVA was limited to finger counting and light perception in the affected eye. Clinical examination revealed proptosis with edema, tenderness 


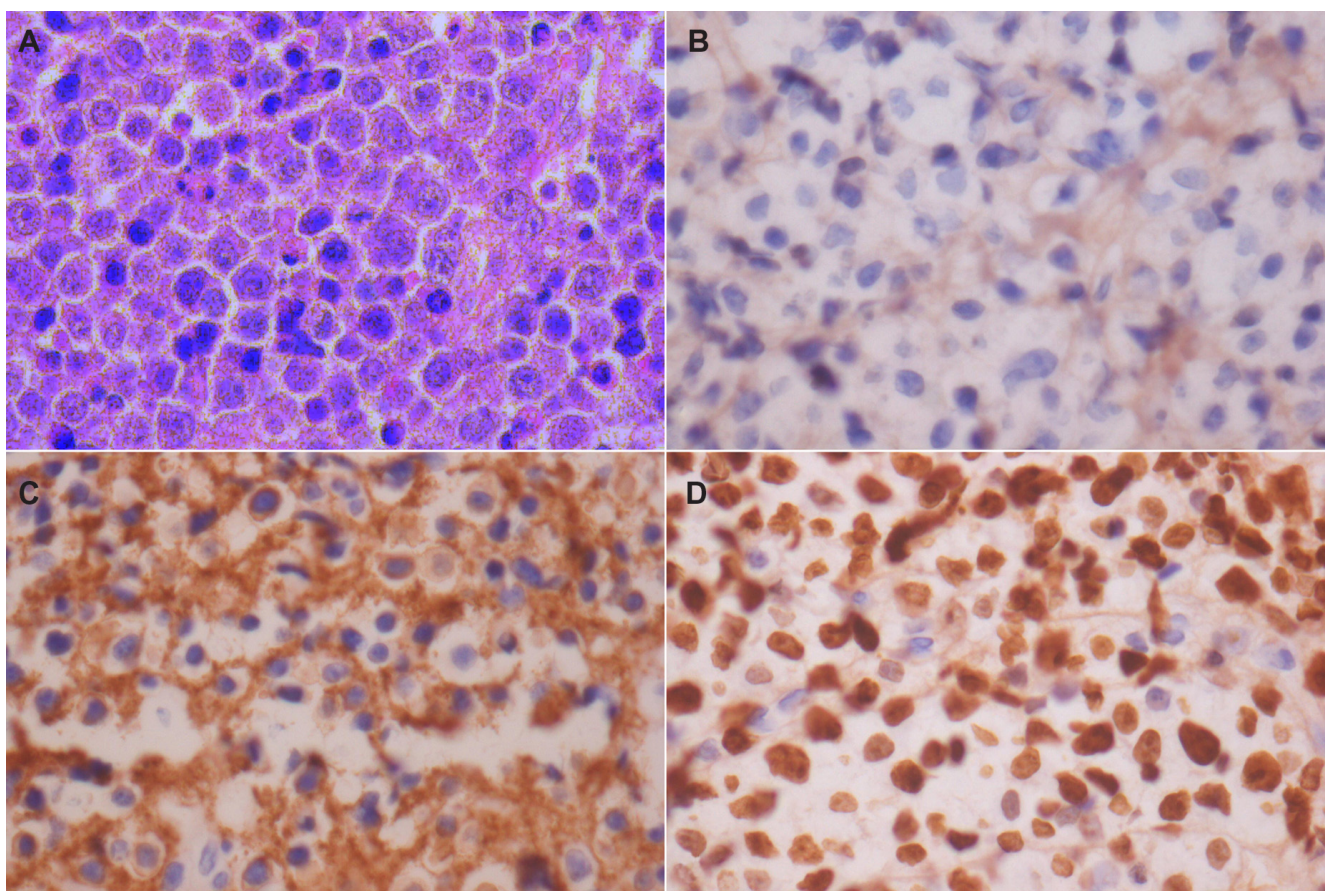

Figure 2 Microphotograph and immunohistochemical staining. Microphotograph showing atypical plasmacytoid tumors cells with abundant amphophilic cytoplasm and a large eccentric vesicular nucleus having a prominent nucleolus $(\mathrm{HE} \times 400)(\mathbf{A})$. Immunohistochemical staining shows lack of immunoreactivity for $\mathrm{CD} 20(\times 400)(\mathbf{B})$. Strong membranous CDI38 immunoreactivity $(\times 400)($ C). Strong Ki-67 immunoreactivity in almost all tumors cells $(\times 400)($ D).

Abbreviation: $\mathrm{HE}$, hematoxylin-eosin.
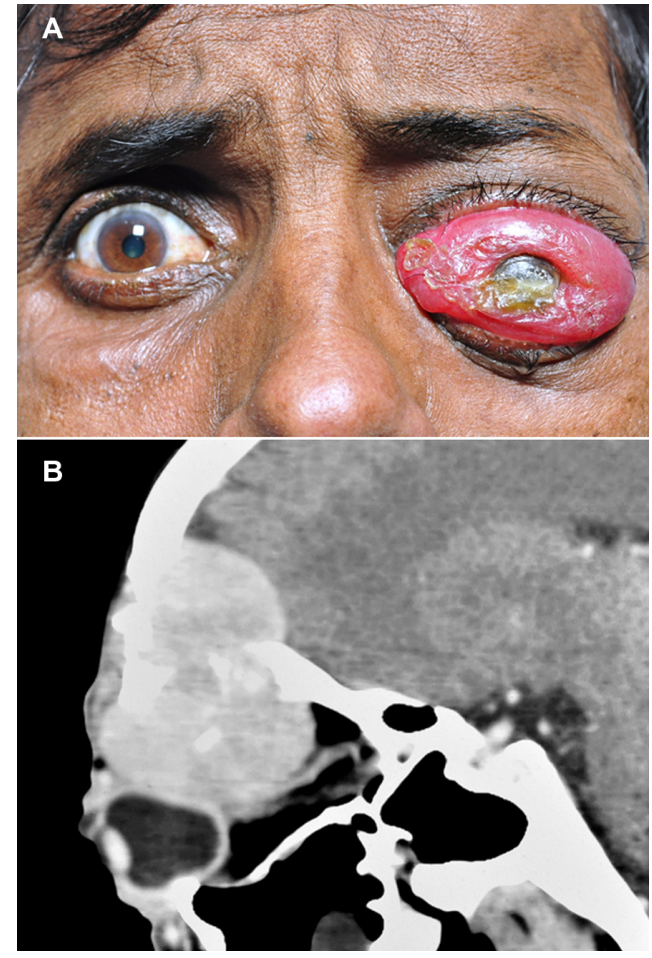

Figure 3 External photograph and CT scan of the patient showing gross proptosis of the left eye with severe conjunctival chemosis, and a large mass lesion in the superior orbit. External photograph of the patient showing gross proptosis of the left eye with severe conjunctival chemosis $(\mathbf{A})$. CT scan with sagittal reconstruction showing a large mass lesion in the superior orbit with extension into the frontal sinus and intracranial space (B).

Abbreviation: $\mathrm{CT}$, computerized tomography and edema of the left upper and lower lids, and complete mechanical ptosis with restricted motility of the globe in all gazes (Figure 4A). Conjunctival chemosis was observed, and the rest of the anterior segment details could not be assessed. Severe periorbital, nonpitting edema with severe tenderness and bluish discoloration of the overlying skin accompanied by skin blistering was seen (Figure 4B). Upper lip edema with blisters were also noted (Figure 4B). A computerized tomography performed at this consultation showed a diffuse mass occupying the entire superior orbit with extension into the temporal fossa and orbital apex with globe compression and stretching of the optic nerve (Figure $4 \mathrm{C}$ and D). An incision biopsy was performed.

Microscopic examination showed a diffuse tumor composed of large plasmablastic cells with eosinophilic to amphophilic cytoplasms and an eccentric vesicular nucleus having prominent nucleoli. Mitotic activity was brisk. Few apoptotic bodies and occasional binucleate cells were also seen. Immunohistochemistry revealed negative staining for CD45 and CD20. Strong membranous positivity for CD138 was observed. The Ki-67 index was 97\%-98\%. This confirmed the diagnosis of a PBL. An HIV screening test was performed and was found to be positive. Bone marrow aspiration did not reveal involvement by PBL. HAART therapy was commenced. Following two cycles of chemotherapy 


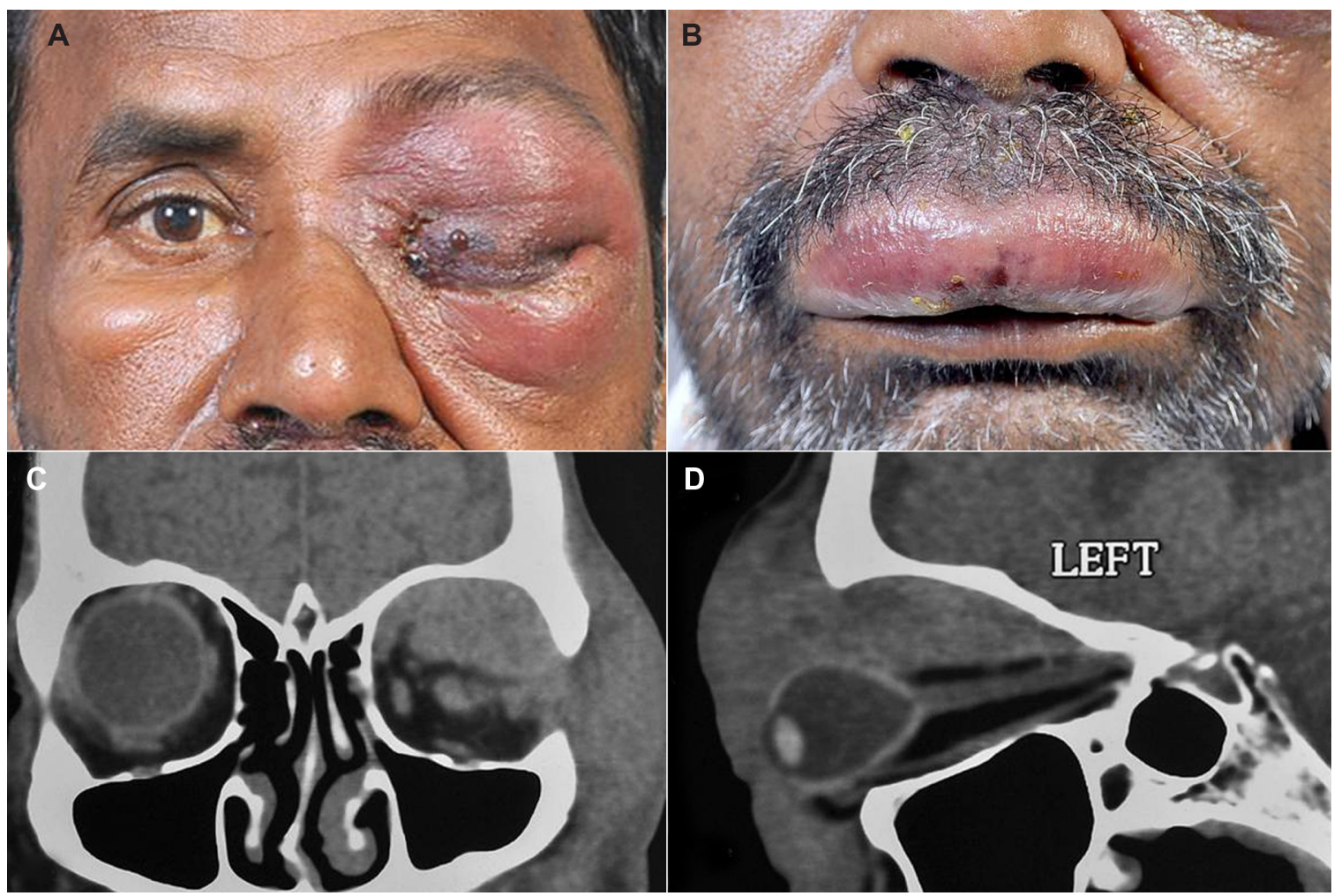

Figure 4 External photograph of the patient showing periocular edema with total ptosis, skin induration, and blisters, as well as lip edema and blisters. External photograph of the patient showing left periocular edema with total ptosis, skin induration, and blisters (A). External photograph showing upper lip edema with blisters (B). CT scan coronal cut of the same patient shows a diffuse ill-defined mass involving the entire superior orbit with superolateral bony erosion and extension into the temporal fossa (C). CT scan with sagittal reconstruction showing diffuse mass involving the entire superior quadrant up to the apex with indentation of the globe and optic nerve stretch (D). Abbreviation: $\mathrm{CT}$, computerized tomography.

that included adriamycin, vincristine, and cyclophosphamide, the patient is still alive at 3 months postdiagnosis with improvement.

\section{Discussion}

PBL is a rare subtype of DLBCL. Ocular involvement by PBL is even rarer. Of all lymphomas diagnosed in our institute, PBL accounted for $0.62 \%$. A large study showed that PBL has a mean age of 39 years at presentation in HIV-positive patients and 54 years in HIV-negative patients. ${ }^{16}$ In patients with ocular involvement, including those in this case series; the mean age at presentation in HIV-positive patients was 44.8 years. PBL presents more commonly in men than women. ${ }^{18}$ Of all the cases of PBL published in the literature with orbital involvement, $71.4 \%$ were males; in our series, $66.6 \%$ were males. ${ }^{9-13} \mathrm{PBL}$ very rarely occurs in children. ${ }^{19-21}$ Table 1 summarizes the clinical, radiological, and histopathological features of ocular PBL reported in the literature.

PBL accounts for $2.6 \%$ of all AIDS-related lymphomas. ${ }^{15}$ In a literature review of 228 cases of PBL, $69 \%$ were HIV-positive while 39\% were HIV-negative. ${ }^{14}$ Moreover, six of seven (85.7\%) PBL affected patients with orbital presentation described in the literature were HIV-positive. In the present study, two of three patients $(66.6 \%)$ were HIV-positive. The association with other immunosuppressive states is conflicting. Some studies have reported some form of immunosuppression in HIV-negative patients with PBL, ${ }^{17}$ while others found no such immunosuppression. ${ }^{21}$ The HIV-negative patient reported by us had no other forms of immunosuppression. Despite the growing literature on PBL, its pathogenesis is still not clear. A large number of molecular and immunohistochemical studies have tried to shed light on this, but no definitive pathogenesis mechanisms have been established. PBL is characterized by immunoblastic morphology and plasma cell phenotype. In other words, plasmablasts are lymphoid cells that morphologically resemble B-cell immunoblasts, but they have acquired a plasma cell immunophenotype. Thus PBL probably develops from postgerminal center, terminally differentiated, active B-cells in transition from immunoblasts to plasma cells. ${ }^{18}$

Recent studies have shown MYC gene rearrangements in PBL. ${ }^{19-22}$ MYC gene rearrangements have not yet been studied on PBL involving the orbit. Most PBL patients are positive for Epstein-Barr virus, thus confirming its role in 
the pathogenesis of PBL. The role of human herpes virus (HHV)-8 in the pathogenesis of PBL remains controversial. Some studies have detected HHV-8 ribonucleic acid in PBL, ${ }^{23,24}$ while others have found negative results. ${ }^{25-27}$ Some studies have documented the simultaneous occurrence of Kaposi sarcoma, Castleman disease, and PBL, thus suggesting further associations with PBL. ${ }^{28}$ None of the cases of PBL involving the orbit have shown a positive association with HHV-8 to date.

A majority of patients with PBL present with diminution of vision and/or proptosis of the affected eye. Conjunctival chemosis, ${ }^{9,10}$ lid swelling, ${ }^{9}$ ptosis, ${ }^{10}$ and a loss of sensation along the trigeminal nerve ${ }^{12}$ are other findings described upon clinical examination. Vision is either reduced or lost in the affected eye. Mild to severe globe motility restriction is a consistent finding on examination. The three patients in the present study showed all of the clinical findings mentioned above in various combinations (Table 2). Computed tomography revealed a soft tissue mass that is usually associated with bony destruction. Involvement of the paranasal sinuses, $9,12,13$ intracranial tissues, ${ }^{11,12}$ nasopharynx,${ }^{13}$ and eyelids ${ }^{10}$ in contiguity may be seen. Involvement of the ethmoid sinus, lid, and temporal fossa was seen in the present series. At presentation, involvement of the liver, bone marrow, or lymph nodes is not uncommon given the highly aggressive nature of PBL. ${ }^{10,13}$ Two patients in the present study had an Ann Arbor stage 1 disease, while one patient showed involvement of bone marrow and liver at presentation (Table 2). Orbital inflammation was the most common differential diagnosis made clinically at presentation. This reflects the challenge posed to the diagnosing physician.

Three categories of PBL have been described in the literature. ${ }^{13,29,30} \mathrm{PBL}$ of the oral mucosa type has a monomorphic population of plasmablasts with minimal or no plasmacytic differentiation. They are found largely in the oral mucosa, but may also occur in other nodal or extranodal sites. PBL with plasmacytic differentiation is composed predominantly of plasmablasts, but exhibits a greater differentiation to mature plasma cells. These cells are round to oval with abundant eosinophilic to amphophilic cytoplasms, an eccentric nucleus, and a prominent nucleolus. Sometimes, a perinuclear Hof may be seen (this is the focal perinuclear clearing seen at the nuclear concavity in plasma cells representing the Golgi zones). ${ }^{18}$ The third type of PBL is associated with Castleman disease and is typically nodal or splenic in its location. ${ }^{31,32}$ In the present study, all of the tumors were PBLs with plasmacytic differentiation.

Syndecan-1 (CD138), CD38, VS38c, and multiple myeloma oncogene, MUM1, are consistently expressed by
PBL. Staining for CD45 and other B-cell markers, CD20 or CD79a, varies from absent to weak immunoreactivity. Reports on CD10, CD56, and Bcl-6 are conflicting. 5,10,12,25 The Ki-67 index is usually around the $100 \%$ mark, thus explaining the highly aggressive nature of PBL. Positive regulatory domain 1 (PRDM1/BL IMP1) protein and activated transcription factor $\mathrm{X}$-box binding protein 1 are proteins that have been recently described to reliably identify $\mathrm{PBL},{ }^{33}$ as they are involved in terminal B-cell differentiation. Plasma cell myeloma, Burkitt's lymphoma, DLBCL, anaplastic lymphoma kinase cell lymphoma with plasmacytoid features, and primary effusion lymphoma are other lymphoproliferative lesions that may exhibit a plasmablastic morphology. Detection of paraproteinemia in the blood and/or excess light chains (Bence-Jones proteins) in the urine, lytic bone lesions, and hypercalcemia or anemia favors the diagnosis of plasma cell myeloma over PBL. Negative or weak staining for PAX5 and CD20 coupled with positive staining for PAX5, as well as CD20 coupled with positive staining for PRDM1/BLIMP1 and X-box binding protein 1 help differentiate PBL from DLBCL; as such, a staining pattern is seen in $<5 \%$ of DLBCL cases. ${ }^{34}$ The strong expression of CD20 and CD79a help to differentiate Burkitt lymphoma from PBL. ALK expression and/or ALK-rearrangement confirm an ALK-positive large cell lymphoma with plasmacytoid features, while HHV-8 immunoreactivity helps to differentiate primary effusion lymphomas. Epstein-Barr virus encoded ribonucleic acid (EBER) in situ hybridization has been positive in a majority of PBL cases involving the orbit, although it can be negative in a minor population of HIV-positive and a large proportion of HIV-negative patients with PBL. ${ }^{14} \mathrm{We}$ suggest a strong CD138, VS38c immunoreactivity coupled with a negative/weak CD20, CD79a reactivity, and detection of EBER to be confirmative of PBL.

PBL is a fatal disease with a rapid clinical course characterized by relapse, or early death, despite treatment. Of all the cases of PBL with orbital presentation described in the literature, only two survived beyond a period of 10 months past diagnosis. No long term follow-up data are available. Two patients in the present study died within 6 months postdiagnosis, while one is on remission at 3 months postdiagnosis.

No validated guidelines are available for treating PBL. Most clinicians end up treating PBL like other lymphomas. CHOP and CHOP-like regimens have been tried with varying intensities; however, intensifying the $\mathrm{CHOP}$ regimen has not been shown to improve overall survival. ${ }^{20}$ Rituximab added to the CHOP regimen does not play a role in the treatment of PBL given the CD20-negative nature of these 
Table I Summary of clinical, radiological, and histopathologic features of ocular plasmablastic lymphomas reported in the literature

\begin{tabular}{|c|c|c|c|}
\hline \multirow[t]{2}{*}{ Parameter } & \multicolumn{2}{|l|}{ Morley et al $^{9}$} & \multirow{2}{*}{$\begin{array}{l}\text { Barkhuysen } \\
\text { et } \mathrm{al}^{12}\end{array}$} \\
\hline & Case I & Case 2 & \\
\hline Age & 40 & 49 & 50 \\
\hline Gender & Male & Male & Female \\
\hline Race & West African & White & NA \\
\hline Presentation & $\begin{array}{l}\text { Nasal congestion and discharge, } \\
\text { swelling over the right cheek. } \\
\text { Decreased vision }\end{array}$ & $\begin{array}{l}\text { Toothache for } 2 \text { months, } \\
\text { intermittent nasal discharge, } \\
\text { left eye prominence, binocular } \\
\text { diplopia on left gaze }\end{array}$ & Proptosis, visual loss, ophthalmoplegia \\
\hline Laterality & Right & Left & Left \\
\hline BCVA & Blind & NA & Reduced \\
\hline Pupils & Poorly reacting, mid dilated. & NA & Isocore. Direct reflex almost absent \\
\hline IOP & $33 \mathrm{~mm} \mathrm{Hg}$ & NA & NA \\
\hline Fundus & Macular folds & NA & NA \\
\hline Proptosis & Present & Present & Present \\
\hline Other findings & Chemosis & Swollen lids & $\begin{array}{l}\text { Anesthesia of left maxillary sinus and ophthalmic } \\
\text { branches of trigeminal nerve }\end{array}$ \\
\hline Globe motility & Restricted on right side & Restricted in all gazes & NA \\
\hline CT scan & $\begin{array}{l}\text { Soft tissue mass in the posterior } \\
\text { one-third of the orbit with extension } \\
\text { through the superior orbital fissure }\end{array}$ & $\begin{array}{l}\text { Mass in the maxillary and } \\
\text { ethmoid sinus with bony } \\
\text { erosion and orbital mass }\end{array}$ & $\begin{array}{l}\text { Abscess in the infratemporal fossa with } \\
\text { extension to the posterior cranial fossa, } \\
\text { maxillary sinus, and orbit. Skull base destruction }\end{array}$ \\
\hline Extranodal involvement & Liver & Absent & NA \\
\hline Lymphadenopathy & Absent & Absent & NA \\
\hline Histomorphology & Plasmacytoid & Plasmacytoid & NA \\
\hline Initial clinical diagnosis & Cellulitis & Cellulitis & Abscess \\
\hline CD45 & NA & Weak & Positive \\
\hline CD20 & Negative & Negative & Negative \\
\hline CDI38 & Positive & Positive & Weak \\
\hline CD79a & Negative & Negative & Weak \\
\hline Vs38c & Positive & Positive & NA \\
\hline $\mathrm{Ki}-67$ & Nearly $100 \%$ & Nearly $100 \%$ & NA \\
\hline Other markers & NA & NA & CD56, CD30, CD 10 are negative \\
\hline EBV-LMP I & Negative & NA & NA \\
\hline HHV-8 & Negative & NA & NA \\
\hline EBER-ISH & Positive & NA & Positive \\
\hline Bone marrow & Positive & Negative & Negative \\
\hline CSF & NA & Positive & NA \\
\hline Stage & 4 & I & I \\
\hline Dead/alive & Dead at 3 months & Dead at 3 months & Alive at 13 months \\
\hline Treatment & CHOP followed by ERBT & $\begin{array}{l}\text { CHOP } \times 10, \text { DHAP, } \\
\text { PmitCEBO }\end{array}$ & $\begin{array}{l}\text { HAART, R-CHOP, } 18 \times \text { IT-Mtx alternative } \\
\text { with cytarabine }\end{array}$ \\
\hline Follow-up course & $\begin{array}{l}\text { Lymphadenopathy, } \\
\text { pleural effusion }\end{array}$ & $\begin{array}{l}\text { Mesenteric and paraaortic } \\
\text { adenopathy, nasal mass, } \\
\text { frontal sinus extension }\end{array}$ & $\begin{array}{l}\text { Skull base reossification and regression } \\
\text { of lymphoma }\end{array}$ \\
\hline
\end{tabular}

Abbreviations: NA, not applicable; K/c/o, known case of; PBL, plasmablastic lymphoma; BCVA, best corrected visual acuity; IOP, intraocular pressure; CT, computerized tomography; GIT, gastrointestinal tract; HIV, human immunodeficiency virus; ALK-I, activin receptor-like kinase-I; EBV-LMP I, Epstein-Barr virus latent membrane protein I; HHV-8, human herpesvirus-8; EBER-ISH, Epstein-Barr virus-encoded ribonucleic acid in situ hybridization; CSF, cerebrospinal fluid; CHOP, cyclophosphamide, hydroxydanorubicin, oncovin, and prednisone; ERBT, external beam radiotherapy; DHAP, dexamethasone, cytarabine, and cisplatin; PmitCEBO, prednisolone, mitoxantrone, cyclophosphamide, etoposide, bleomycin, and vincristine; HAART, highly active antiretroviral therapy; R-CHOP, rituximab-cyclophosphamide, hydroxydanorubicin, oncovin, and prednisone; IT-Mtx, intrathecal methotrexate; EPOCH, etoposide, doxorubicin, vincristine, prednisone, and cycolophosphamide; GI, gastrointestinal.

tumors, although it could be added in those with a weak CD20 expression. Chemotherapy has been shown to yield an overall response rate of $77 \%$. HIV-positive patients who discontinue or do not initiate HAART show a higher rate of relapse. ${ }^{20}$ A combination of HAART and chemotherapy increases the response rate..$^{35,36}$ etoposide, doxorubicin, vincristine, prednisone, and cycolophosphamide (EPOCH), cyclophosphamide, vincristine, doxorubicin, methotrexate, ifosfamide, etoposide and cytarabine (CODOX-M/ IVAC), dexamethasone, cytarabine, and cisplatin (DHAP), 


\begin{tabular}{|c|c|c|c|}
\hline \multirow{2}{*}{$\begin{array}{l}\text { Valenzuela } \\
\text { et al }{ }^{10}\end{array}$} & \multirow{2}{*}{$\begin{array}{l}\text { Degnan } \\
\text { et al' }\end{array}$} & \multicolumn{2}{|l|}{ Colomo et $\mathrm{al}^{13}$} \\
\hline & & Case I & Case 2 \\
\hline 41 & 43 & 37 & 55 \\
\hline Female & Male & Male & Male \\
\hline Caucasian & Caucasian & NA & NA \\
\hline Upper lid induration, K/c/o buccal PBL & $\begin{array}{l}\text { Proptosis, headache, eye pain. } \\
\text { Jaw abscess } 3 \text { months ago }\end{array}$ & NA & NA \\
\hline Right & Left & NA & NA \\
\hline NA & NA & NA & NA \\
\hline NA & NA & NA & NA \\
\hline NA & NA & NA & NA \\
\hline NA & NA & NA & NA \\
\hline NA & NA & NA & NA \\
\hline Chemosis, complete ptosis. & NA & NA & NA \\
\hline Restricted & NA & NA & NA \\
\hline $\begin{array}{l}\text { Mass in anterior orbit extending from preseptal } \\
\text { tissues of the lid to the lacrimal gland involving } \\
\text { the extraconal tissues }\end{array}$ & $\begin{array}{l}\text { Retro-orbital mass with erosion of the sphenoid } \\
\text { wing. Mass in the left temporal lobe and the right } \\
\text { fossa of Rosenmuller }\end{array}$ & $\begin{array}{l}\text { Primary maxillary origin } \\
\text { with orbital extension }\end{array}$ & NA \\
\hline Lungs, GIT, liver & NA & NA & NA \\
\hline Positive & Positive & Positive & Positive \\
\hline Immunoblastic & Medium- to large-sized & Immunoblastic & Immunoblastic \\
\hline NA & NA & NA & NA \\
\hline Positive & NA & Negative & Negative \\
\hline Negative & NA & Negative & Negative \\
\hline Positive & Positive & Positive & Positive \\
\hline Negative & Weak & Negative & Negative \\
\hline NA & NA & NA & NA \\
\hline $100 \%$ & NA & NA & NA \\
\hline Weak CDIO and Bcl6; negative & CDI0 positive & NA & NA \\
\hline CDE, bcl2 ALK-I, CD30, CD56 & & & \\
\hline NA & NA & NA & Negative \\
\hline NA & NA & NA & NA \\
\hline Positive & NA & Negative & Positive \\
\hline Positive & NA & NA & NA \\
\hline NA & NA & NA & NA \\
\hline 4 & NA & NA & 4 \\
\hline Death on second day & Alive at 10 months & NA & $\begin{array}{l}\text { Death at } \\
7 \text { months }\end{array}$ \\
\hline Was on HAART & Pegfilgastrim, EPOCH & NA & NA \\
\hline Bleeding and ulceration from & Size reduced in 2 months; 5 months remission. & NA & NA \\
\hline Gl lymphoma & $\begin{array}{l}\text { Lesion in retromandibular and cervical nodes, and } \\
\text { new lesion in the fossa of Rosenmueller at } 10 \text { months }\end{array}$ & & \\
\hline
\end{tabular}

prednisolone, mitoxantrone, cyclophosphamide, etoposide, bleomycin, and vincristine (PmitCEBO), and bischloroethylnitrosourea, etoposide, cytarabine, melphalan (BEAM) have been tried in PBL with little or no success. ${ }^{9,20}$ Autologous stem cell transplantation has been experimented in PBL, but the follow-up data has not encompassed a long enough time-frame to conclude its effectiveness. ${ }^{37}$ Responses to bortezomib have been encouraging, but the data available is limited. ${ }^{38}$ Overall, the treatment of PBL is quite puzzling; it thus poses a therapeutic challenge to clinicians. 
Table 2 Clinicopathological features of cases of plasmablastic lymphoma included in the present study

\begin{tabular}{|c|c|c|c|}
\hline \multirow[t]{2}{*}{ Feature } & \multicolumn{3}{|l|}{ Present study } \\
\hline & Case I & Case 2 & Case 3 \\
\hline Age & 45 & 45 & 48 \\
\hline Sex & Female & Male & Male \\
\hline Race & Asian Indian & Asian Indian & Asian Indian \\
\hline Clinical presentation & Proptosis, diminished vision & Swelling of upper lid & Trauma, redness, watering, pain \\
\hline Laterality & Right & Left & Left \\
\hline Vision & Finger counting & Light perception & Finger counting \\
\hline Clinical examination & $\begin{array}{l}\text { Proptosis, globe motility, } \\
\text { restriction, macular folds }\end{array}$ & Chemosis & $\begin{array}{l}\text { Periorbital swelling, upper lip swelling, } \\
\text { mechanical ptosis, globe motility } \\
\text { restriction, chemosis, proptosis }\end{array}$ \\
\hline CT scan & $\begin{array}{l}\text { Mass in superolateral orbit } \\
\text { with bony erosion and spread } \\
\text { to temporal fossa }\end{array}$ & $\begin{array}{l}\text { Mass in anterior orbit with bony } \\
\text { erosion and extension into cranial } \\
\text { fossa, frontal, and ethmoid sinus }\end{array}$ & $\begin{array}{l}\text { Orbital mass extending to apex } \\
\text { with stretching of optic nerve }\end{array}$ \\
\hline Systemic examination & No significant findings & Hepatomegaly, multiple liver deposits & Fever \\
\hline HIV status & Negative & Positive & Positive \\
\hline Clinical diagnosis & Lacrimal gland tumor, lymphoma & Lacrimal gland tumor, ES/PNET & Orbital cellulitis \\
\hline Histopathology & Atypical plasmactoid cells & Atypical plasmacytoid cells & Atypical plasmacytoid cells \\
\hline CD45 & Negative & Weak & Negative \\
\hline CD20 & Negative & Negative & Negative \\
\hline CD79a & $\mathrm{N} / \mathrm{P}$ & $\mathrm{N} / \mathrm{P}$ & $\mathrm{N} / \mathrm{P}$ \\
\hline CDI38 & Positive & Positive & Positive \\
\hline VS38c & $\mathrm{N} / \mathrm{P}$ & $\mathrm{N} / \mathrm{P}$ & $\mathrm{N} / \mathrm{P}$ \\
\hline Ki-67 & $98 \%$ & Close to $100 \%$ & $97 \%-98 \%$ \\
\hline EBER-ISH & $\mathrm{N} / \mathrm{P}$ & $\mathrm{N} / \mathrm{P}$ & $\mathrm{N} / \mathrm{P}$ \\
\hline HHV-8 & N/P & $\mathrm{N} / \mathrm{P}$ & $\mathrm{N} / \mathrm{P}$ \\
\hline $\mathrm{BM}$ & Negative & Positive & Negative \\
\hline Treatment & Could not be initiated & Refused & $\begin{array}{l}\text { Adriamycin, vincristine, } \\
\text { cyclophosphamide, HAART }\end{array}$ \\
\hline F/U course & Rapid worsening & Lost on F/U & Burnt out tumor \\
\hline Death & 2 weeks & 6 months & Alive at 6 months \\
\hline
\end{tabular}

Abbreviations: CT, computerized tomography; HIV, human immunodeficiency virus; ES/PNET, Ewing sarcoma/primitive neuroectodermal tumor; EBER-ISH, Epstein-Barr virus-encoded ribonucleic acid in situ hybridization; HHV-8, human herpesvirus-8; BM, bone marrow; F/U, follow-up; HAART, highly active antiretroviral therapy; N/P, not performed.

The recent advancement has been the identification of a loss of p16 and MDR-1 in PBL. ${ }^{39}$

\section{Conclusion}

Orbital involvement by PBL, although rare, is seen with a higher prevalence in HIV-positive individuals. Recent studies on MYC translocation and the positive identification of EBER have tried to explain the pathogenesis of PBL and its aggressive nature, yet the exact pathogenic mechanisms remain elusive. Morphological and immunohistochemical characteristics overlap with other lymphoproliferative lesions, which pose a diagnostic challenge to the pathologist. Though the treatment of PBL has revolved around CHOP and CHOP-like regimens, no validated treatments are currently available. Features at presentation simulate an inflammatory process, thus making PBL a clinical challenge. Further research is recommended to develop an effective treatment. Lastly, given the aggressive nature of PBL and its propensity to early death despite treatment, early clinical diagnosis may increase the overall survival of such patients.

\section{Acknowledgments}

This study has been reviewed by the ethics committee and has been performed in accordance with the ethical standards laid down in the 1964 Declaration of Helsinki. Informed consent was obtained from the patients.

\section{Disclosure}

The authors report no conflicts of interest in this work.

\section{References}

1. Bairey O, Kremer I, Rakowsky E, Hadar H, Shaklai M. Orbital and adnexal involvement in systemic non-Hodgkin's lymphoma. Cancer. 1994;73(9):2395-2399.

2. Swerdlow SH. Tumour of haematopoietic and lymphoid tissues. In: Swerdlow SH, Campo E, Harris NL, editors. World Health Organization Classification of Tumors. 4th ed. Lyon, France: International Agency for Research on Cancer Press; 2008. 
3. Delecluse HJ, Anagnostopoulos I, Dallenbach F, et al. Plasmablastic lymphomas of the oral cavity: a new entity associated with the human immunodeficiency virus infection. Blood. 1997;89(4):1413-1420.

4. Chabay P, De Matteo E, Lorenzetti M, et al. Vulvar plasmablastic lymphoma in a HIV-positive child: a novel extraoral localisation. J Clin Pathol. 2009;62(7):644-646.

5. Thakral C, Thomas L, Gajra A, Hutchison RE, Ravizzini GC, Vajpaynee N. Plasmablastic lymphoma in an immunocompetent patient. J Clin Oncol. 2009;27(25):e78-e81.

6. Khurana A, Jalpota Y. Plasmablastic lymphoma in a human immunodeficiency virus negative patient. Indian J Pathol Microbiol. 2010;53(2): 368-369.

7. Brahmania M, Sylwesterowic T, Leitch H. Plasmablastic lymphoma in the ano-rectal junction presenting in an immunocompetent man: a case report. $J$ Med Case Rep. 2011;5:168.

8. Kim JE, Kim YA, Kim WY, et al. Human immunodeficiency virus-negative plasmablastic lymphoma in Korea. Leuk Lymphoma. 2009;50(4): 582-587.

9. Morley AM, Verity DH, Meligonis G, Rose GE. Orbital plasmablastic lymphoma - comparison of a newly reported entity with diffuse large B-cell lymphoma of the orbit. Orbit. 2009;28(6):425-429.

10. Valenzuela AA, Walker NJ, Sullivan TJ. Plasmablastic lymphoma in the orbit: case report. Orbit. 2008;27(3):227-229.

11. Degnan AJ, Levy LM. Orbital plasmablastic lymphoma with remission following chemotherapy. J Radiology Case Rep. 2011;5(2):1-7.

12. Barkhuysen R, Merkx MA, Weijs WL, Gerlach NL, Bergé SJ. Plasmablastic lymphoma mimicking orbital cellulitis. Oral Maxillofac Surg. 2008;12(3):125-128.

13. Colomo L, Loong F, Rives S, et al. Diffuse large B-cell lymphomas with plasmablastic differentiation represent a heterogeneous group of disease entities. Am J Surg Pathol. 2004;28(6):736-747.

14. Castillo JJ, Winer ES, Stachurski D, et al. Clinical and pathological differences between human immunodeficiency virus-positive and human immunodeficiency virus-negative patients with plasmablastic lymphoma. Leuk Lymphoma. 2010;51(11):2047-2053.

15. Carbone A, Gloghini A. Plasmablastic lymphoma: one or more entities? Am J Hematol. 2008;83(10):763-764.

16. Castillo J, Pantanowitz L, Dezube BJ. HIV-associated plasmablastic lymphoma: lessons learned from 112 published cases. Am J Hematol. 2008;83(10):804-809.

17. Rafaniello Raviele P, Pruneri G, Maiorano E. Plasmablastic lymphoma: a review. Oral Dis. 2009;15(1):38-45.

18. Castillo JJ, Reagan JL. Plasmablastic lymphoma: a systematic review. Scientific World Journal. 2011;11:687-696.

19. Dawson MA, Schwarer AP, McLean C, et al. AIDS-related plasmablastic lymphoma of the oral cavity associated with an IGH/MYC translocation - treatment with autologous stem-cell transplantation in a patient with severe haemophilia-A. Haematologica. 2007;92(1):e11-e12.

20. Castillo JJ, Winer ES, Stachurski D, et al. Prognostic factors in chemotherapy-treated patients with HIV-associated Plasmablastic lymphoma. Oncologist. 2010;15(3):293-299.

21. McGlaughlin KL, Bajel A, Mow CD. A case of plasmablastic lymphoma harbouring an $\mathrm{IgH} / \mathrm{MYC}$ translocation in a HIV negative individual Pathology. 2010;42(7):697-699.

22. Bogusz AM, Seegmiller AC, Garcia R, Shang P, Ashfaq R, Chen W Plasmablastic lymphomas with MYC/IgH rearrangement: report of three cases and review of the literature. Am J Clin Pathol. 2009;132(4):597-605.

Clinical Ophthalmology

\section{Publish your work in this journal}

Clinical Ophthalmology is an international, peer-reviewed journal covering all subspecialties within ophthalmology. Key topics include: Optometry; Visual science; Pharmacology and drug therapy in eye diseases; Basic Sciences; Primary and Secondary eye care; Patient Safety and Quality of Care Improvements. This journal is indexed on Submit your manuscript here: http://www.dovepress.com/clinical-ophthalmology-journal
23. Dong HY, Scadden DT, de Leval L, Tang Z, Isaacson PG, Harris NL. Plasmablastic lymphoma in HIV-positive patients: an aggressive Epstein-Barr virus-associated extramedullary plasmacytic neoplasm. Am J Surg Pathol. 2005;29(12):1633-1641.

24. Carbone A, Gloghini A, Gaidano G. Is plasmablastic lymphoma of the oral cavity an HHV-8-associated disease? Am J Surg Pathol. 2004; 28(11):1538-1540; author reply 1540.

25. Vega F, Chang CC, Medeiros LJ, et al. Plasmablastic lymphomas and plasmablastic plasma cell myelomas have nearly identical immunophenotypic profiles. Mod Pathol. 2005;18(6):806-815.

26. Brown RS, Power DA, Spittle HF, Lankester KJ. Absence of immunohistochemical evidence for human herpesvirus 8 (HHV8) in oral cavity plasmablastic lymphoma in an HIV-positive man. Clin Oncol (R Coll Radiol). 2000;12(3):194.

27. Carbone A, Gloghini A, Canzonieri V, Tirelli U, Gaidano G. AIDSrelated extranodal non-Hodgkin's lymphomas with plasma cell differentiation. Blood. 1997;90(3):1337-1338.

28. Cioc AM, Allen C, Kalmar JR, Suster S, Baiocchi R, Nuovo G. Oral plasmablastic lymphomas in AIDS patients are associated with human herpesvirus 8. Am J Surg Pathol. 2004;28(1):41-46.

29. Teruya-Feldstein J. Diffuse large B-cell lymphomas with plasmablastic differentiation. Curr Oncol Rep. 2005;7(5):357-363.

30. Tavora F, Gonzalez-Cuyar LF, Sun CC, Burke A, Zhao XF. Extra-oral plasmablastic lymphoma: report of a case and review of literature. Hum Pathol. 2006;37(9):1233-1236.

31. Dupin N, Diss TL, Kellam P, et al. HHV-8 is associated with a plasmablastic variant of Castleman disease that is linked to HHV-8-positive plasmablastic lymphoma. Blood. 2000;95(4):1406-1412.

32. Oksenhendler E, Boulanger E, Galicier L, et al. High incidence of Kaposi sarcoma-associated herpesvirus-related non-Hodgkin lymphoma in patients with HIV infection and multicentric Castleman disease. Blood. 2002;99(7):2331-2336.

33. Schebesta M, Harvey B, Busslinger M. Transcriptional control of B-cell development. Curr Opin Immunol. 2002;14(2):216-223.

34. Montes-Moreno S, Gonzalez-Medina AR, Rodriguez-Pinilla SM, et al. Aggressive large B-cell lymphoma with plasma cell differentiation: immunohistochemical characterization of plasmablastic lymphoma and diffuse large B-cell lymphoma with partial plasmablastic phenotype. Haematologica. 2010;95(8):1342-1349.

35. Teruya-Feldstein J, Chiao E, Filippa DA, et al. CD20-negative largecell lymphoma with plasmablastic features: a clinically heterogeneous spectrum in both HIV-positive and -negative patients. Ann Oncol. 2004;15(11):1673-1679.

36. Lester R, Li C, Phillips P, et al. Improved outcome of human immunodeficiency virus-associated plasmablastic lymphoma of the oral cavity in the era of highly active antiretroviral therapy: a report of two cases. Leuk Lymphoma. 2004;45(9):1881-1885.

37. Goto H, Hagiwara S, Hirai R, et al. Case of relapsed AIDS-related plasmablastic lymphoma treated with autologous stem cell transplantation and highly active antiretroviral therapy. Rare Tumors. 2011;3(1):e11.

38. Dunleavy K, Pittaluga S, Czuczman MS, et al. Differential efficacy of bortezomib plus chemotherapy within molecular subtypes of diffuse large B-cell lymphoma. Blood. 2009;113(24):6069-6076.

39. Matsuki E, Miyakawa Y, Asakawa S, et al. Identification of loss of p16 expression and upregulation of MDR-1 as genetic events resulting from two novel chromosomal translocations found in plasmablastic lymphoma of the uterus. Clin Cancer Res. 2011;17(8):2101-2109.

\section{Dovepress}

PubMed Central and CAS, and is the official journal of The Society of Clinical Ophthalmology (SCO). The manuscript management system is completely online and includes a very quick and fair peer-review system, which is all easy to use. Visit http://www.dovepress.com/ testimonials.php to read real quotes from published authors. 